\title{
RUIN PROBABILITIES IN DEPENDENT INSURANCES WITH AUTOREGRESSIVE MODEL
}

\author{
DOI: 10.17261/Pressacademia.2018.997 \\ JBEF- V.7-ISS.4-2018(6)-p.365-375
}

\section{Elif Makbule Cekici ${ }^{1}$, Sami Ozcan², Hasan Durmus ${ }^{3}$}

${ }^{1}$ Marmara University, Faculty of Business Administration, Goztepe Campus, Istanbul, Turkey. ecekici@marmara.edu.tr, ORCID: 0000-0002-1603-9896

${ }^{2}$ Ardahan University, Faculty of Economics and Administrative Sciences, Yenisey Campus, Ardahan, Turkey. samiozcan@ardahan.edu.tr, ORCID: 0000-0002-7654-7614

${ }^{3}$ Eskisehir Osmangazi University, Faculty of Economics and Administrative Sciences, Meselik Campus, Eskisehir, Turkey. hasan.durmuss@gmail.com, ORCID: 0000-0001-8240-4671

Date Received: November 8, 2018

Date Accepted: December 23, 2018

To cite this document

Cekici, E. M., Ozcan, S., Durmus, H. (2018). Ruin probabilities in dependent insurances with autoregressive model. Journal of Business, Economics and Finance (JBEF), V.7(4), p.365-375

Permenant link to this document: http://doi.org/10.17261/Pressacademia.2018.997

Copyright: Published by PressAcademia and limited licensed re-use rights only.

\begin{abstract}
Purpose- Risk analysis and ruin probabilities were calculated with the assumption of independence in the past, however this assumption does not reflect the reality at the present time. Today, insurance activities are more advanced, and consumers are more informed, for this reason existence of dependency between insurance branches within the portfolio of an insurance firm, is unavoidable. Aim of this study is to calculate the ruin probability for two dependent insurance branches.

Methodology- In this study, monthly claim data of a leading insurance firm which belongs to two different insurance branches namely traffic and health, in the period of 2007-2016 are used.

Findings- In the case of fixed interest rate and initial capital, it's found that if dependence of insurance branches decreases, ruin probabilities decrease.

Conclusion- In the case of fixed interest rate and initial capital, to decrease the ruin probability, dependence of branches should be decreased. To lower the dependence, collected premiums should be increased, thus lower adjustment coefficients can be obtained. Accordingly, with the lower adjustment coefficient, ruin probabilities can be decreased.
\end{abstract}

Keywords: Ruin probability, dependent ruin probability, multivariate autoregressive process (MAR(1)), 2-parameter exponential distribution.

JEL Codes: C32, G22, I13

\section{INTRODUCTION}

History of insurance goes long way back. First insurance policy was done in Italy in late 14. century. With marching along time, insurance transactions were rapidly developed in 20 . century. While insurance activities were concentrated especially on sea transportation in the past, insurance activities for different branches were began to be done. Since insurance transactions for different insurance branches were evaluated independently till 1990s, transactions and models with assumption of independence were done. However especially from the beginning of 1990s, along with the rise of different insurance transactions for same person or organizations, any claim existed in one policy began to affect another policy directly. For this reason, independence assumption used in calculations and models fell from favor.

Especially for modern day insurance firms, it is so difficult to accept independence assumption in many calculations like modelling processes, claims and determining claims' distributions etc. Therefore, independence assumption lost validity in modelling ruin probabilities too.

In this study firstly dependent ruin probabilities and classic ruin probabilities in actuarial models, types of dependences and dependent ruin probabilities were mentioned. In the second part, autoregressive model used in dependent ruin probabilities was discussed. In practice part, monthly claim data of a leading insurance firm which belongs to two different insurance branches namely traffic and health, in the period of 2007-2016 are used and by establishing autoregressive model and analyzing dependence level of delayed values, dependent ruin probabilities were tried to calculate. 


\section{LITERATURE REVIEW}

$\mathrm{Wu}$ and Yuen (2003), proposed a discrete time risk model (interactive model) for interactive dependent classes of firms. They argued that within the context of this model, any risk existed within a class, is affected not only from its own risk, but also risk from other classes. They firstly explained interactive model through number of distribution family and then compared with other results from literature by numeric example. Consequently, they showed that if numbers of dependent classes increase, risk increases.

Wan, Yuen and Li (2005) studied discrete time risk model with m-number $(m \geq 2)$ dependent classes of insurance firm. Its assumed that claim processes for $m$ number classes fit multivariate autoregressive time series. In the study, by assuming claims are limited as exponential in proposed claim model, ultimate ruin probability was investigated. By taking claims with two parameter exponential and gamma distributions, examples were given with simulations.

The study done by Cai and Li (2007) focused on three commonly used ruin probabilities and showed how some ruin probabilities increase by using comparison methods and how ruin probabilities decrease with the rise of claim dependences. Paper also offers explicit calculated limits with multivariate phase type distributed claims for these ruin probabilities. Besides, shows performance of these limits for multivariate composed Poisson risk models with mildly or highly dependent Marshall - Olkin exponential claim amounts.

Dağlıoğlu and Erdemir (2008a), discussed process distributions which fit moving autoregressive average models related to insurers income and premium and claim processes' first order autoregressive models when premiums are collected in fixed amounts. They investigated the effects of changes in process mean, initial capital and interest rate and dependence between claims' present and past periods on ruin probabilities. Simulation technique was applied for experimental results and consequently they showed every factor has special effects on ruin probabilities.

In Dağlıoğlu and Erdemir's (2008b) study, explanation of premium and claim variables of dependent insurance branches within a portfolio fitting multivariate first order autoregressive model was done with numeric examples. Ruin probabilities were calculated with data generated by simulation in case of premiums are collected as fixed c amount at the beginning of period and claim processes fit two variables first order autoregressive model. They concluded changes in initial capital, interest rate and fixed premium amounts influenced upper limits of ruin probabilities.

Liosel and Lefevre (2009) discoursed on two generalized models which combined poisson risk model and claims fit Poisson distribution. They focused not only the inhomogeneity in premium amounts and claims, but also probable dependency between claim amounts. They discussed on ruin probability calculations for these risk models.

In the study done by Heilpern (2009) two-dimension, dependent Poisson risk process was investigated. Claims were separated into two different classes and its been thought that in every class claims can have same distribution and claims in different classes can have different distributions. Besides, effects of claim classes dependency on ruin probabilities were investigated with the assumption of dependency of claim count processes.

Cossette, Marceau and Deschamps (2010) discussed dependency of claim distribution numbers for each period with various time series approaches (Poisson moving average process (Poisson MA(1)), Poisson autoregressive process (Poisson AR(1)), Markov-Bernoulli process and Markov transition process) in their study. They gave numerical examples to compare the results. They investigated relationship between adjustment coefficient and dependency coefficient for every process and their effects on ruin probabilities. Consequently, they stated that there is a relationship between adjustment coefficient and dependency coefficient and accordingly ruin probabilities were influenced from this situation.

In Gu (2013)'s study, being focused on Farlie-Gumbel-Morgenstern (FGM copula) rested claim amounts and expansion of risk model which has dependency between claim times. For this purpose, Erlang (2) dependent risk model, generalized Lundberg disequilibrium and integro-differential equation which is Gerber-Shiu penalty function were derived.

Jiang and Yang (2016), expanded compound Poisson distribution with FGM copula to examine the distribution of maximum residuals before ruin in case claim depends on time occurred. They derived integro-differential equilibrium with specific limit conditions for the distribution provided Laplace transformation.

\section{THE CONCEPTUAL FRAMEWORK}

\subsection{Actuarial Dependency}

The idea of claims which will occur in calculations of ruin probabilities and claim amount are independent and random was popular in actuary for long years. However, with the developments in insurance transactions, it was seen by firms that insurances affect each other significantly. For this reason, studies in actuary science, went towards dependency assumption, instead of assumption of independency. 
It is possible to mention two types of dependency in actuarial models. First type of dependency arises between policies of one firm's different insurance branches or between different insurance branches directly. On the other hand, second type can be stated as the dependency between claim or premium processes and past claim and premium processes. (Dağlıoğlu and Erdemir, 2008a: 106).

For an insurance firm, relationship between claim amounts which make $S$, the probable total claim amount, can be handled within the concept of common monotony and correlation. Wang and Dhaene (1998), explain common monotony and correlation concepts as follows:

Cumulative distribution function for a claim amount, $X$ ( $X$ real valued nonnegative random variable with finite average) is shown as (cdf) $F_{X}(X)=P\{X \leq X\}$, and for another claim amount $Y\left(Y\right.$ so as to provide same conditions) as cdf $F_{Y}(y)=P\{Y \leq Y\}$. Joint cumulative distribution function is shown as $F_{X, Y}(X, Y)=P\{X \leq X, Y \leq y\}$ for $X$ and $Y$ claim couple $\left(Y_{1}, Y_{2}\right)$

$$
F_{X, Y}(x, y)=P\{X \leq x, Y \leq y\}=\min \left(F_{X}(x), F_{Y}(y)\right) \forall y_{1}, Y_{2} \geq 0
$$

If its ensured, $X$ and $Y$ called as common monotony. $\left(X_{1}, Y_{1}\right)$ and $\left(X_{2}, Y_{2}\right)$, as being two member of $R\left(F_{X}, F_{Y}\right)$, one of the equalities below must be provided, to obtain that $\left(X_{1}, Y_{1}\right)$ couple has a lower correlation than $\left(X_{2}, Y_{2}\right)$. $f$ and $g$ functions are as nondecreasing functions,

$$
\begin{array}{ll}
\operatorname{Cov}\left(f\left(X_{1}\right), g\left(Y_{1}\right)\right) \leq \operatorname{Cov}\left(f\left(X_{2}\right), g\left(Y_{2}\right)\right) & \\
F_{X_{1}, Y_{1}}(x, y) \leq F_{X_{2}, Y_{2}}(x, y) & \forall x, y \geq 0
\end{array}
$$

\subsection{Ruin Probability}

Classical ruin theory was proposed by Lundberg in 1907 and developed by Cramer in 1930. This theory can be defined as, evolution of an insurance firm's fiscal surplus (difference between collected premiums and claims in a period, in case Premium amount is more than claims) along a period of time. According to the assumption of classical ruin theory, insurance firm begins with initial capital and collects a fixed amount of premiums continuously. Ruin occurs when the money paid by firm (claim amount) is more than the collected money (premium amount). In other words, if fiscal surplus is equal to zero or negative (Tse, 2009: 143), ruin exists. In actuary science, ruin probability is used as a risk measure. In accordance with this purpose, actuaries and scientists study on new models by using advanced mathematical techniques to use at calculation of ruin probabilities. These studies increased the interest on ruin theory not only theorical but also practical (Yang, 2003: 135).

Generally, in investigation of ruin theory, two different approaches are used namely, discrete time processes and continuous time processes. In discrete time processes, $X_{n}$ shows premiums collected from the beginning of period $n$ to time $n, Y_{n}$ presents claims paid till the end of $n$ period and $R_{n}$ presents short term interest rate in $n$. period. Thus, surplus at the end of $n$ period, $U_{n}$ can be defined as follows (Yang ve Zhang, 2006; 290):

$$
U_{n}=\left(U_{n-1}+X_{n}\right)\left(1+R_{n}\right)-Y_{n}
$$

At equation (4), $X_{n}, R_{n}$ and $Y_{n}$ are independent identically distributed random variables. Ruin occurs if expected value of claim payments in a period is more than expected value of collected premiums in the same period. Accordingly, $\psi(u)$ as showing ultimate ruin probability, can be shown as follows.

$$
\psi(u)=P(T(u)<\infty)
$$

Then, getting a negative value for the first time at $\mathrm{T}(\mathrm{u})$, which means ruin probability for a process, begins with $u$ initial capital, can be expressed as (5). If there is no claim payment at any " 1 " time with a probability of $f_{x}(0)$, residuals pile towards 1 and then ultimate ruin probability is $\psi(1)$ (Tse, 2009: 146). This can be shown as follows:

$$
\psi(0)=f_{X}(0) \psi(1)+S_{X}(0)
$$

Here $S_{X}(0)=1-F_{X}(0)=P(X \geq 1)$. Similarly, if $u=1$, then $\psi(1)$ can be calculated as:

$$
\psi(1)=f_{x}(0) \psi(2)+f_{x}(1) \psi(1)+S_{x}(1)
$$

If these calculations are generalized, following equation can be obtained.

$$
\psi(u)=f_{x}(0) \psi(u+1)+\sum_{j=1}^{u} f_{x}(j) \psi(u+1-j)+S_{x}(u), \quad u \geq 1
$$

After rearranging equation (8), ultimate ruin probability can be written as follow: 


$$
\psi(u+1)=\frac{1}{f_{x}(0)}\left[\psi(u)-\sum_{j=1}^{u} f_{x}(j) \psi(u+1-j)-s_{x}(u)\right] \quad u \geq 1
$$

To apply this equation, $\psi(0)$ the initial capital given at following theorem is needed. For discrete time residual model, it is $\psi(\mathrm{u})=\mu_{\mathrm{x}}$. Here $\mu_{\mathrm{x}}$ represents expected value of claims paid and can be calculated as below:

$$
\psi(0)=\sum_{u=0}^{\infty} S_{x}(u)=\mu_{x} \quad \text { or } \quad \sum_{u=0}^{\infty} f_{x}(u) S_{x}(u)=\mu_{x}
$$

On the other hand, in continuous time ruin models, its assumed that claim occurrences fit Poisson distribution. If $\left\{\mathrm{S}_{\mathrm{t}}: \mathrm{t} \geq 0\right\}$ shows total claim process and $X_{j}$ represents j'nd claim process (Heilpern, 2009: 77);

$$
\mathrm{S}_{\mathrm{t}}=\sum_{\mathrm{i}=1}^{\mathrm{N}_{\mathrm{t}}} \mathrm{x}_{\mathrm{i}} \quad \text { and } \quad \mathrm{U}_{\mathrm{t}}=\mathrm{u}+\mathrm{ct}-\mathrm{S}_{\mathrm{t}}
$$

equation can be written. $(0, t]$ showing net premium revenue, $c$ showing premium amount in unit of time, premiums can be expressed with ct. If at any time period, premium revenue of insurance firm is more than expected value of claims paid at the same period is accepted, then $c>\lambda m$ can be said. Thus, following relation can be obtained.

$$
c=(1+\theta) \lambda m
$$

$\theta>0$, is called premium loading factor; $\lambda$, concentration parameter of poisson distribution and $m=E\left(X_{i}\right)$. According to equations thus far, $U_{0}=u$ as being initial capital, $T$ time of riun and ruin probability $(\psi(u))$ can be calculated as follow:

$$
\begin{aligned}
& \mathrm{T}=\inf \left\{\mathrm{t}: \mathrm{U}_{\mathrm{t}}<0\right\} \\
& \psi(\mathrm{u})=\mathrm{P}\left(\mathrm{T}<\infty \mid \mathrm{U}_{0}=\mathrm{u}\right)
\end{aligned}
$$

When $U_{t}$ is negative, ruin occurs. If $c \leq \lambda m$ then $\theta \leq 0$ and this time $\psi(u)=1$.

Zang et al. (2007), stated total residual amount of firm $U_{n}$ as,

$$
\mathrm{U}_{\mathrm{n}}=\mathrm{U}_{1 \mathrm{n}}+\mathrm{U}_{2 \mathrm{n}}+\ldots \ldots \ldots+\mathrm{U}_{\mathrm{pn}} \quad \mathrm{n} \geq 0
$$

if number of dependent insurance branches is $p$. Here $U_{0}=u=u_{1}+u_{2}+\ldots \ldots u_{p}$ is sum of initial capitals.

\subsection{Ruin Probability in Dependent Insurance}

$1 \leq i \leq p$ and $W_{\text {in }}$, shows total premium amount collected at period $n$ and $Z_{\text {in }}$ shows claims paid at the same period. $W_{\text {in }}$ and $Z_{\text {in }}$ being nonnegative random variables, if premium amount collected at period $n$ is collected at the beginning of period and claims paid at the same period is paid at the end of period is assumed, total residual amount $U_{n}$ can be expressed as follow:

$$
U_{n}=u(1+r)^{n}+\sum_{i=1}^{p} \sum_{k=1}^{n} w_{i k}(1+r)^{n-k+1}-\sum_{i=1}^{p} \sum_{k=1}^{n} z_{i k}(1+r)^{n-k}
$$

Here $r$ is the fixed interest rate. $U_{n}$ can be written by matrices as follow:

$$
\mathrm{U}_{\mathrm{n}}=\mathrm{v}^{-1} \mathrm{U}_{\mathrm{n}-1}+\mathrm{v}^{-1} \mathbf{1}_{\mathrm{p}}{ }_{\mathrm{p}} \mathbf{W}_{\mathrm{n}}-\mathbf{1}_{\mathrm{p}}^{\prime} \mathbf{z}_{\mathrm{n}} \quad \mathrm{n} \geq 1
$$

$v=(1+r)^{-1}$ shows discount factor, $\mathbf{1}_{k}$, k-dimension column vector composed of $1 s, W_{n}=\left(W_{1 n}, \ldots . ., W_{p n}\right)^{\prime}$ column vector of fixed premium amount collected at the beginning of $n^{\prime} n d$ period and $Z_{n}=\left(Z_{1 n}, \ldots . . ., Z_{p n}\right)^{\prime}$ column vector of claim amount paid at the end of period $n$. So, $T$ showing the time of ruin, ruin probability $\phi(u, w, z)$ is expressed as;

$$
\begin{aligned}
& T=\min \left\{n \geq 0: U_{n}<0\right\} \quad \min \varphi=+\infty \\
& \phi(u, w, z)=P\left(T<\infty \mid U_{0}=u, W_{0}=w, Z_{0}=z\right)
\end{aligned}
$$

Here $u$ shows initial residual, $\mathbf{w}$ initial premium and $\mathbf{z}$ claims paid. Also ruin probability, $\mathrm{R}$ the adjustment coefficient, can be expressed as below:

$$
\phi(u, w, z) \leq \frac{e^{(-R \hat{u})}}{E\left[e^{\left(-R v^{\top} \widehat{U}_{T}\right)} \mid T<\infty\right]}
$$

$\widehat{U}_{\mathrm{N}}$ and its components can be calculated as follows. 


$$
\begin{aligned}
& \widehat{U}_{n}=U_{n}+a^{\prime} \mathbf{W}_{n}-b^{\prime} z_{n} \\
& U_{0}=\hat{u}=u+a^{\prime} \mathbf{w}-b^{\prime} z \\
& \mathbf{a}=\left(\alpha_{1}, \ldots \ldots \alpha_{p}\right) \text { ve } \mathbf{b}=\left(\beta_{1}, \ldots \ldots \beta_{p}\right) \text { constant vector } \\
& \left(a^{\prime}, b^{\prime}\right)=\left(\mathbf{1}^{\prime}{ }_{p^{\prime}}-v \mathbf{1}^{\prime}{ }_{p}\right) A\left(I_{2 p^{\prime}}-v A\right)^{-1} \\
& A=\left(\begin{array}{ll}
A_{1} & A_{2} \\
B_{1} & B_{2}
\end{array}\right) \\
& A_{1}=\left(a_{i j}\right)_{1 \leq i, j \leq p^{\prime}} A_{2}=\left(a_{i j}\right)_{1 \leq i \leq p, p+1 \leq j \leq 2 p} \\
& \quad B_{1}=\left(a_{i j}\right)_{p+1 \leq i \leq 2 p, 1 \leq j \leq p^{\prime}}, B_{2}=\left(a_{i j}\right)_{p+1 \leq i, j \leq 2 p}
\end{aligned}
$$

The condition of premium revenue exceeding claim payments in every period is called as net premium condition. In dependent risks modelled with time series assumption, since premium and claim processes are generally unknown, net premium condition is written by using independent and identically distributed error terms. As a result of this, the adjustment coefficient $\mathrm{R}$ is obtained by the distribution of error terms. Besides, since error terms are independent and identically distributed random variables, its sufficient to obtain adjustment coefficient with the distribution of first error term (Dağlığlu ve Erdemir, 2008b: 149).

Net Premium condition for first order multivariate autoregressive model can be written as follows, when ruin probability for a risk model is considered (Zhang vd., 2007: 34).

$$
v^{-1} E\left[\sum_{i=1}^{p} W_{i k}\right]>E\left[\sum_{i=1}^{p} z_{i k}\right] \quad k \geq 1
$$

Since distributions of $\mathrm{W}_{\mathrm{ik}}$ and $\mathrm{Z}_{\mathrm{ik}}$ are generally unknown, net premium condition can be written in terms of $\mathbf{V}$, which shows independent and identically distributed error terms.

$$
\left(v^{-1} \mathbf{1}_{p}^{\prime}, \mathbf{1}_{p}^{\prime}\right)\left[\frac{I_{2 P}-A^{k}}{I_{2 P}-A}\left(\begin{array}{l}
E(\mathbf{X}) \\
E(\mathbf{Y})
\end{array}\right)+A^{k}\left(\begin{array}{l}
\mathbf{w} \\
\mathbf{z}
\end{array}\right)\right]>0 \quad k \geq 1
$$

Net Premium condition is sufficient condition if only ruin probability is less than 1 . The necessary condition for ruin probabilities less than 1 in first order multivariate autoregressive model is as follows.

$$
E\left[\left(v^{-1} \mathbf{1}_{p}+\mathbf{a}\right)^{\prime} X-\left(\mathbf{1}_{p}+\mathbf{b}\right)^{\prime} Y\right]>0
$$

$\mathbf{a}$ and $\mathbf{b}$ constant vectors as said before. If the conditions at (24) is granted, A as being coefficient matrix, $r$ interest rate and $\mathrm{F}$ distribution function, $\left\{\varepsilon_{\mathrm{n}}\right\}$ process showing independent and identically distributed random variables series described by general distribution function can be expressed as below.

$$
\varepsilon_{\mathrm{n}}=\left(\mathrm{v}^{-1} \mathbf{1}_{\mathrm{p}}+\mathbf{a}\right)^{\prime} \mathbf{X}_{\mathrm{n}}-\left(\mathbf{1}_{\mathrm{p}}+\mathbf{b}\right)^{\prime} \mathbf{Y}_{\mathrm{n}}
$$

Here $E\left[\varepsilon_{n}\right]>0$. Thus, the adjustment coefficient $R$, can be obtained by solving following equation.

$$
E\left[e^{\left(-R \varepsilon_{1}\right)}\right]=1
$$

If there are more than one solution for (26), minimum of these should be chosen as R. As its seen, if there is a positive constant $R^{\prime}$, supplying $E\left[e^{\left(-R^{\prime} \varepsilon_{1}\right)}\right] \geq 1$, it should be the adjustment coefficient.

\subsection{Autoregressive Models Used in Dependent Ruin Probability}

Time series are sets of sorted measurements of an amount (Bayramoğlu, 2018: 18). Aim of making analysis with time series is to understand the reality representing by observation set and predicting future values of time series variables correctly.

Autoregressive (AR) processes are the processes showing the relation of time series with their past values. Dependent variable is a function of past values in an autoregressive model. One variable autoregressive model $(\operatorname{AR}(1))$ is shown as follows.

$$
\mathrm{x}_{\mathrm{t}}=\alpha+\beta \mathrm{x}_{(\mathrm{t}-1)}+\varepsilon
$$

At equation (27), $x_{t}$ shows the value of $x$ variable at time $t, \alpha$ constant of model, $\beta$ relation with past period, $x_{(t-1)}$ : last period value of $x$ variable and $\varepsilon$ error. Time series were first used for premium revenue prediction in actuary science. After 
that besides premium, time series was set into motion for claim predictions used in ruin probability. Thanks to these studies, autoregressive models got more importance in actuary studies.

First order autoregressive model used for premium processes in actuarial models is described as follows (Dağlıoğlu and Erdemir, 2008a: 107).

$$
W_{n}=Y_{n}+b W_{n-1}
$$

Here, $W_{n}$, shows premium amount collected in period $n, W_{n-1}$ shows Premium amount collected in previous period, and $Y_{n}$ is the series of independent and identically distributed nonnegative random variables. Parameter $b$ in the model shows the relation of premium amount in period $n$ with previous period and $0 \leq b \leq 1$. While $b$ approaching 1 refers the strong relationship of premium process with past periods, approaching 0 refers a weak relationship.

Claim processes fit first order autoregressive model similarly and is expressed as below.

$$
Z_{n}=X_{n}+a Z_{n-1}
$$

Like premium processes, $Z_{n}$ shows claim amount paid at period $n, Z_{n-1}$ shows claim amount paid at previous period and $X_{n}$ is series of independent and identically distributed nonnegative random variables. Here parameter a shows relationship of claim process with past periods and $0 \leq a \leq 1$.

As a result of investigations done in this study, its seen that premium and claim processes can be modelled with first order autoregressive model. Thus, premium and claim processes were tried to be modelled with first order autoregressive model. Besides, multivariate autoregressive model can be described as a multivariate model explained with delayed values of premium and claim variables for each branch and all other variables within the system.

Let $\left(Z_{1 n}, Z_{2 n}\right)$ is the claim paid in the period $n$, within a portfolio consist of two dependent insurance branches in case of premiums are collected in fixed amounts. Also, let in claim processes $\left\{\left(Z_{1 n}, Z_{2 n}\right)\right\}$, initial values for every dependent class are like $Z_{10}=z_{1}$ and $Z_{20}=z_{2} \cdot\left(Z_{1 n}, Z_{2 n}\right)$ claim processes fit two variable autoregressive $(A R(1))$ time series model as follows (Zhang vd.: 37).

$$
\begin{aligned}
& Z_{1 n}=\alpha_{1} Z_{1(n-1)}+\alpha_{2} Z_{2(n-1)}+X_{n} \\
& Z_{2 n}=b_{1} Z_{1(n-1)}+b_{2} Z_{2(n-1)}+Y_{n}
\end{aligned} \quad n \geq 1
$$

Here $\alpha_{i}$ and $b_{i}$ are nonnegative constants and $\left\{\left(X_{n}, Y_{n}\right)\right\}$ processes are independent and identically distributed nonnegative random vector processes.

In actuarial models, stationary assumption is needed for consistency and applicability of models along time. Stationary is important in terms of consistency of model. Stationary in time series is the condition of mean and variance of random variable is the same along time. If its multivariate, covariance should be stable.

Stationary condition for any time series which fit two variable autoregressive model like equation (30) is that all roots of $\lambda$ should be less than 1.

$$
h(\lambda)=\left|\begin{array}{cc}
\lambda-a_{1} & -a_{2} \\
-b_{1} & \lambda-b_{2}
\end{array}\right|=\left(\lambda-a_{1}\right)\left(\lambda-b_{2}\right)-a_{2} b_{1}=0
$$

Since $a_{i}$ and $b_{i}$ variables at equation (31) are not negative, stationary condition can be expressed as follows:

$$
a_{1}+b_{2}-a_{1} b_{2}+a_{2} b_{1}<1
$$

In dependent risks modelled with time series approach, its said before that adjustment coefficient $R$ can be obtained by the help of distribution of error terms. If error terms of two dependent insurance branches claim amount as $Z_{1 n}$ and $Z_{2 n}$ which fit two order autoregressive model, respectively $X_{n} \sim \exp (\alpha)$ and $Y_{n} \sim \exp (\beta)$ have an exponential distribution, its shown at (33); (Dağlıoğlu and Erdemir, 2008b: 151)

$$
E\left(X_{n}\right)=\frac{1}{\alpha} \quad E\left(Y_{n}\right)=\frac{1}{\beta}
$$

If error terms of claim processes $\left(\xi_{k}\right)$ are being;

$$
\begin{aligned}
\xi_{k}=[1 & \left.+\alpha\left(v^{-1}\right)\right] X_{k}+\left[1+\beta\left(v^{-1}\right)\right] Y_{k} \\
= & \frac{\left[v^{-2}+\left(b_{1}-b_{2}\right) v^{-1}\right] X_{k}+\left[v^{-2}-\left(a_{1}-a_{2}\right) v^{-1}\right] Y_{k}}{h\left(v^{-1}\right)}
\end{aligned}
$$

then can be obtained as follows: 


$$
\begin{aligned}
E\left(\xi_{k}\right) & =\frac{\left[v^{-2}+\left(b_{1}-b_{2}\right) v^{-1}\right] E\left(X_{k}\right)+\left[v^{-2}-\left(a_{1}-a_{2}\right) v^{-1}\right] E\left(Y_{k}\right)}{h\left(v^{-1}\right)} \\
& =\frac{\left[v^{-2}+\left(b_{1}-b_{2}\right) v^{-1}\right] \frac{1}{\alpha}+\left[v^{-2}-\left(a_{1}-a_{2}\right) v^{-1}\right] \frac{1}{\beta}}{h\left(v^{-1}\right)}
\end{aligned}
$$

As being $\mathrm{E}\left(\xi_{\mathrm{k}}\right)=1 / \lambda$, R adjustment coefficient, can be obtained by solving the equation (36).

$$
\exp \left(\operatorname{Rcv}^{-1}\right)=\frac{\lambda}{\lambda-R}
$$

\section{DATA AND METHODOLOGY}

\subsection{Used Data Set}

In the study, its aimed to calculate ruin probabilities in case of dependency of claim payments for two insurance branches. Simulated data take place in literature generally and calculations are done according to some assumptions. However, in this case it is possible to have difficulties to apply obtained results to the actual observations. In this context, monthly claim data of a leading insurance firm in Turkey which belongs to two different insurance branches namely traffic and health, in the period of 2007-2016 are used. These two branches were chosen according to the expectation of theoretical dependency between them. Analysis were done by simplifying claim amounts with 10.000 .000 for the ease of calculation.

\subsection{Descriptive Findings about Insurance Branches}

Descriptive findings for paid claim amounts of branches are summarized in Figure 1 and Figure 2.

Figure 1: Descriptive Findings of Traffic Insurance Claim Amounts (TICA)

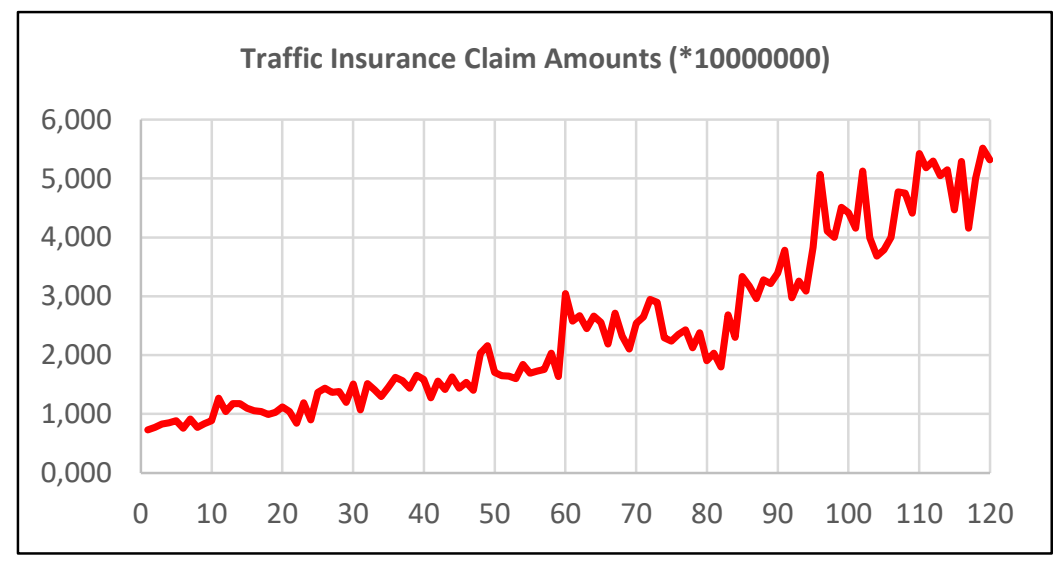

\begin{tabular}{|ll|}
\hline Descriptive Findings & \\
Number of Obs.: & 120 \\
Mean: & 2,43 \\
Std. Deviation: & 1,373 \\
Max: & 5,514 \\
Min: & 0,731 \\
Range: & 4,783 \\
\hline
\end{tabular}

There are 120 observation value for traffic insurance in the period of 2007 January - 2016 December. It is obviously seen from the graph that there is a rising trend. In that period, monthly average claim payment is 24,3 million TL with a standard deviation of approximately 1,4 million TL. While the biggest claim payment is 55,143 million TL, minimum payment is 47,83 million TL. This shows that the payment range is 47,83 which can be evaluated as a bigger one. 
Figure 2: Descriptive Findings for Health Insurance Claim Amounts (HICA)

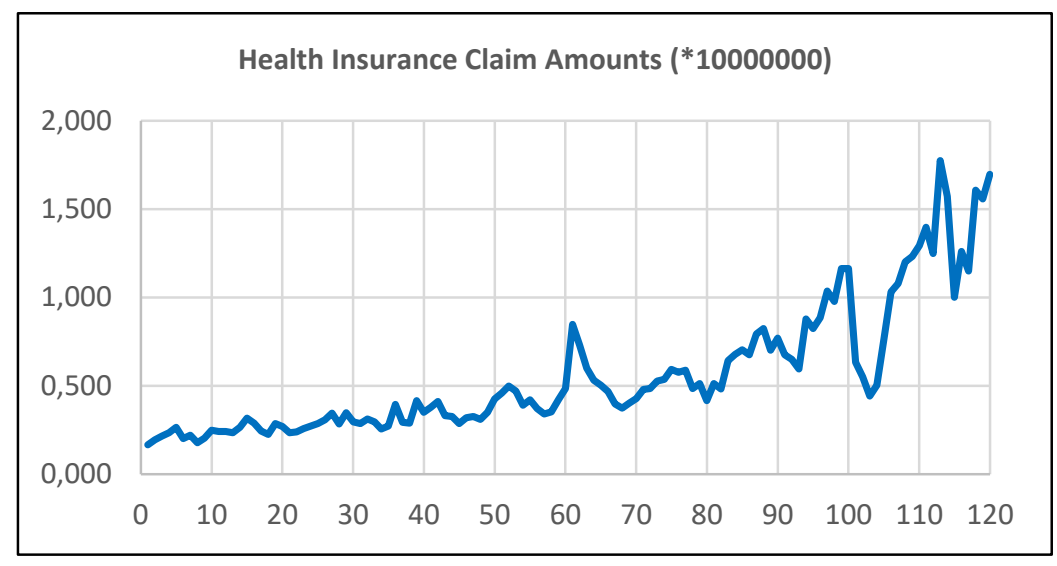

\begin{tabular}{|ll|}
\hline Descriptive Findings & \\
Number of Obs.: & 120 \\
Mean: & 0,563 \\
Std. Deviation: & 0,369 \\
Max: & 1,774 \\
Min: & 0,165 \\
Range: & 1,609 \\
\hline
\end{tabular}

There are 120 observation value for traffic insurance in the period of 2007 January - 2016 December like traffic insurance. It is obviously seen from the graph that there is a rising trend for this branch too. Only in 2005, there is a serious decrease, but rise continues after that. In the period, monthly average claim payment is 5,63 million TL with a standard deviation of approximately 0,4 million TL. While the biggest claim payment is 17,742 million TL, minimum payment is 1,650 million TL. This shows that the payment range is 16,092 which can be evaluated as a bigger one. Although range of health insurance is not as big as traffic insurance, when we take the amounts paid into account, it can be said that situation is not different from the other one.

In the study, it's thought that traffic and health insurances are dependent. To examine this covariance and correlation coefficients were calculated. As a result of calculation, covariance ( $\left.\operatorname{Cov}_{\mathrm{TICA}, \mathrm{HICA}}\right)$ is 46,088 . Covariance is significantly different from zero shows that there is a dependency between health and traffic insurances in terms of claim payments. However, since interpreting covariance value is difficult, determining correlation coefficient based on covariance provides stronger comments. (Makridakis, Wheelwright and Hyndman, 1998: 37). Thus, correlation coefficient ( $\rho$ (TICA, HICA )) was obtained as 0,91 . After evaluating covariance and correlation values together, it can be said that there is a strong dependency between paid claim amounts of traffic and health insurances.

There are 120 observations for both insurance branches. For the examination of distributions Minitab 18 was used. Results of TICA and HICA variables' distribution tests were given at the following Table 1.

Table 1: Results of TICA and HICA Variables' Distribution Tests

\begin{tabular}{|l|c|c|c|c|c|c|}
\hline \multirow{2}{*}{ Distribution } & \multicolumn{3}{|c|}{ TICA } & \multicolumn{3}{c|}{ HICA } \\
\cline { 2 - 7 } & AD & P & LRT P & AD & P & LRT P \\
\hline Normal & 4,017 & $<0,005$ & & 6,908 & $<0,005$ & \\
\hline Lognormal & 1,057 & 0,009 & & 1,398 & $<0,005$ & \\
\hline 3-Parameter Lognormal & 0,894 & $*$ & 0,087 & 0,307 & $*$ & 0,000 \\
\hline Exponential & 11,161 & $<0,003$ & & 10,865 & $<0,003$ & \\
\hline 2-Parameter Exponential & 1,078 & 0,088 & 0,000 & 1,247 & 0,054 & 0,000 \\
\hline Weibull & 2,005 & $<0,010$ & & 3,522 & $<0,010$ & \\
\hline Gamma & 1,582 & $<0,005$ & & 2,761 & $<0,005$ & \\
\hline 3- Parameter Gamma & 0,598 & $*$ & 0,000 & 0,989 & $*$ & 0,000 \\
\hline Logistic & 3,479 & $<0,005$ & & 5,157 & $<0,005$ & \\
\hline Loglogistic & 1,220 & $<0,005$ & & 1,322 & $<0,005$ & \\
\hline 3- Parameter Loglogistic & 1,041 & $*$ & 0,018 & 0,394 & $*$ & 0,000 \\
\hline
\end{tabular}

\section{at 0,05 significance level}

When we analyze Table 1, its seen that both variables' distributions fit 2-parameter exponential distribution in which $p$ values are more than 0,05 . After determining distributions, parameters of distributions were calculated and presented in Table 2. 
Table 2: TICA and HICA Variables' Distribution Parameters

\begin{tabular}{|l|c|c|}
\hline Variable & Distribution Parameter $(\boldsymbol{\lambda})$ & Threshold Parameter \\
\hline TICA & 1,71340 & 0,71703 \\
\hline HICA & 0,40136 & 0,16167 \\
\hline
\end{tabular}

There are two parameters for 2-parameter exponential distribution which are $\lambda$ and threshold parameter. According to results by maximum likelihood (ML) method, for TICA variable $\lambda=1,7134$ and threshold $=0,71703$ and for HICA variable $\lambda=$ 0,40136 and threshold $=0,16167$. Distribution graphics for both variables are presented in Figure 3 .

\section{Figure 3: Graphics of Probability Distribution Tests for TICA and HICA Variables}

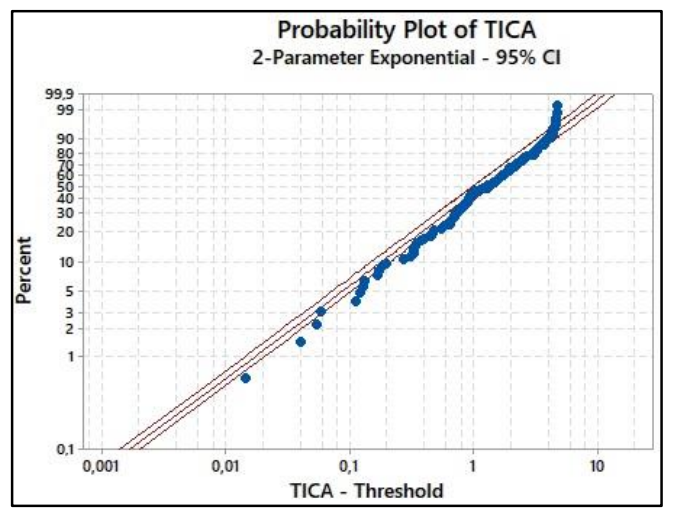

(a) TICA Variable

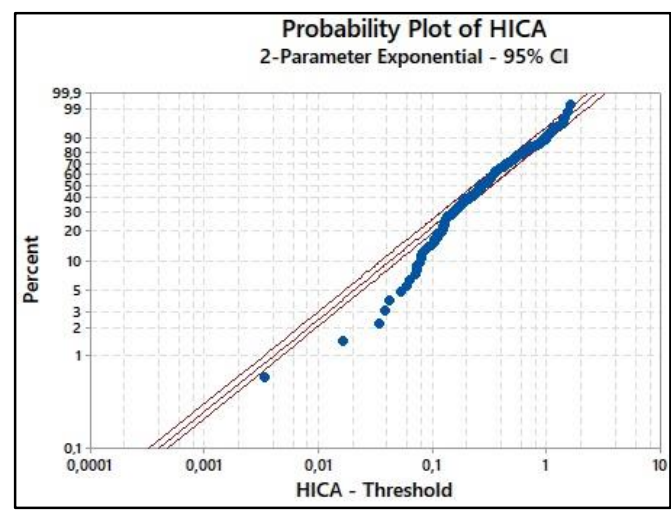

(b) HICA Variable

It can be said that they are located within limits according to threshold values by evaluating graphic and distribution test results and therefore they fit to 2 parameter exponential distribution. It is possible to say that distribution graphics and distribution test results confirm each other.

\subsection{Conformity Analysis for Autoregressive Processes}

Results of analysis of multivariate autoregressive model which generated by dependency of TICA and HICA variables taken in this study, are presented at Table 5.

Table 3: Results of Autoregressive Model Analysis

\begin{tabular}{|c|c|c|c|c|c|}
\hline & Variable & Coefficient & Std. Error & t-statistic & Prob. \\
\hline \multirow{2}{*}{$Z_{\text {TICA(n) }}$} & $\operatorname{TICA}(-1)$ & 0.415425 & 0.059651 & 13.66982 & 0.0000 \\
\hline & $\mathrm{HICA}(-1)$ & 0.311540 & 0.250369 & 3.241381 & 0.0015 \\
\hline & $\mathrm{R}^{2}$ & 0.913421 & \multicolumn{2}{|c|}{ Akaike Inf. Criteria (AIC) } & 5.650771 \\
\hline \multicolumn{2}{|l|}{ Adjusted $\mathrm{R}^{2}$} & 0.912681 & \multicolumn{2}{|c|}{ Schwarz Inf. Criteria (SC) } & 5.697479 \\
\hline \multirow{2}{*}{$Z_{\text {HICA(n) }}$} & $\operatorname{TICA}(-1)$ & 0.034757 & 0.018395 & 3.520348 & 0.0006 \\
\hline & $\mathrm{HICA}(-1)$ & 0.213325 & 0.077207 & 9.627636 & 0.0000 \\
\hline \multirow{2}{*}{\multicolumn{2}{|c|}{ Adjusted $\mathrm{R}^{2}$}} & 0.886381 & \multicolumn{2}{|c|}{ Akaike Inf. Criteria (AIC) } & 3.297892 \\
\hline & & 0.885410 & \multicolumn{2}{|c|}{ Schwarz Inf. Criteria (SC) } & 3.344600 \\
\hline
\end{tabular}

When analyzing Table 3, results of analysis of determined autoregressive models for both TICA and HICA variables shows that $R^{2}$ values are pretty high, also AIC and SC values are seen as sufficient. Accordingly, multivariate autoregressive models for two variables are as follows:

$$
\begin{aligned}
& Z_{T I C A(n)}=0,42 Z_{T I C A(n-1)}+0,31 Z_{H I C A(n-1)}+X_{n} \\
& Z_{T I C A(n)}=0,03 Z_{T I C A(n-1)}+0,21 Z_{H I C A(n-1)}+X_{n}
\end{aligned}
$$

Hereunder, TICA depends on previous TICA by \% 41,5425 and previous HICA by the rate of \% 31, 154. On the other hand, HICA is dependent to previous period HICA by $\% 21,3325$ and previous period TICA by $\% 3,4757$. 


\subsection{Ruin Probabilities}

In many studies seen in literature since claim amounts distributions are unknown, calculations were done by error terms of claim amounts. However, in this study theoretical distributions and parameters of these distributions for traffic and health insurances, consisting of 120 observations, were determined. Therefore, instead of distributions of error terms, determined distributions and parameters which belong real observation values, were used.

Within the scope of this study, collected premiums for traffic and health were taken together. In this period, ruin probabilities according to average total premium, minimum total premium and maximum total premium were summarized in Table 4.

Table 4: Ruin Probabilities for Different Total Premiums

\begin{tabular}{|c|c|c|c|c|c|}
\hline $\begin{array}{c}\text { Collected } \\
\text { Premiums (c) }\end{array}$ & $\begin{array}{c}\text { Fixed Interest } \\
\text { Rate } \\
(\mathbf{r})\end{array}$ & $\begin{array}{c}\text { Initial Capital (u) } \\
(\mathbf{*} \mathbf{1 0 0 0 0 0 0 0 )}\end{array}$ & $\begin{array}{c}\text { Stationary } \\
\text { Condition } \\
(\mathbf{h}(\boldsymbol{\lambda}) \mathbf{)}\end{array}$ & $\begin{array}{c}\text { Adjustment } \\
\text { Coefficient (R) }\end{array}$ & $\begin{array}{c}\text { Ruin Probability } \\
(\boldsymbol{\phi})\end{array}$ \\
\hline 0,9 & 0 & 10 & 0,4489 & 0,0062 & 0,94 \\
\hline 2,99 & 0 & 10 & 0,4489 & 0,015 & 0,86 \\
\hline 7,29 & 0 & 10 & 0,4489 & 0,192 & 0,15 \\
\hline 10 & 0 & 10 & 0,4489 & 0,229 & 0,1 \\
\hline
\end{tabular}

Values in collected premium column were taken as total collected premium of traffic and health insurances in the same period. Obtained minimum total premium amount, average premium amount and maximum total premium were considered. Besides, of set purpose that collected premium were increased along time, ruin probability was calculated in case of collected total premium was $100.000 .000 \mathrm{TL}$ in two branches. Fixed interest rate was accepted as 0 and initial capital was assumed stable. Its seen that stationary condition was confirmed by verifying that the values in the column were less than 1. Adjustment coefficient was calculated with MATLAB R2013 by bisection method. It was calculated with nonzero minimum positive value and 0,01 tolerance.

Following the calculations, it was seen that if total collected premium in two branches is $9.000 .000 \mathrm{TL}$, ruin probability is $94 \%$, in case of total collected premium is $29.900 .000 \mathrm{TL}$, ruin probability is $\% 86$, in case of total collected premium is $72.900 .000 \mathrm{TL}$, ruin probability is $15 \%$ and in case of total collected premium is $10.000 .000 \mathrm{TL}$, ruin probability is $10 \%$.

\section{EMPIRICAL RESULTS}

In this study, calculation of ruin probabilities in case of two branches of an insurance firm are dependent, was aimed. In many similar studies, data were generated by simulations generally and ruin probabilities were calculated with assumptions. In the scope of this study, actualized real data were used for analysis and results were interpreted. Obtained results are in accordance with similar studies in literature.

On condition that interest rate and initial capital is fixed, its seen that while adjustment coefficient increases, ruin probabilities decrease. To decrease ruin probability, increasing adjustment coefficient $R$ is enough, as mentioned in studies of Wan, Yuen and Li (2005) and Dağlıoğlu and Erdem (2008b). Rise of R is probable with the decrease of dependency between insurance branches. As a result of this decreasing ruin probability can be obtained. However, since dependency of branches taken in the study is extremely high, expecting the decrease in dependency is futile.

Another way to decrease ruin probabilities in case of fixed initial capital and interest rate is to increase collected premiums. If collected premiums can be increased in two branches, since total premiums can exceed claim amounts, ruin probabilities will decrease. When obtained results were evaluated together, in case of total premium is $9.000 .000 \mathrm{TL}$, adjustment coefficient is 0,0062 and ruin probability is $94 \%$. When collected premium is $29.900 .000 \mathrm{TL}$, adjustment coefficient is 0,015 and ruin probability decreases to $86 \%$. In the same way, when collected premium is $72.900 .000 \mathrm{TL}$, adjustment coefficient is 0,192 and ruin probability is $15 \%$. Finally, if collected premium increases to $100.000 .000 \mathrm{TL}$, adjustment coefficient is 0,229 and ruin probability is $10 \%$. To sum up, according to these findings, it can be said that collected premium raises adjustment coefficient and correspondingly reduces ruin probability.

\section{CONCLUSION}

Since dependency between insurance branches increases ruin probability, studies that diminishing dependency can be supposed, but when current conditions and competition at insurance sector is considered, it is not seen as possible to decrease the dependency. For this reason, it is important for a firm to not to have a depletion in portfolio when taking precautions for customers. Also, total premiums can be increased and with new customers by empowering insurance consciousness, thus ruin probability can be decreased. The conditions which create dependency between branches can be determined by analyzing actual claim payments. In this way, these effects can be separated from each other in policies for both present customers and new customers. 
Measuring dependency between existing branches for insurance firms is very important. Calculating ruin probabilities and making risk assessment by considering in what way the dependency is and how strong it is, can be very important guide in decision making for future.

If we think branches as investment portfolio, considering that portfolio risk can be decreased by diversification, then we can make out that increasing diversification in independent branches will decrease ruin probability. Thus, premium that comes to premium pond will increase and risk factor which effects firms' general situation will be decreased.

In this study, 120 actual observation value is taken belonging two insurance branches which are supposed to be dependent. In this context, dependency of more than two branches can be measured and ruin probabilities can be calculated accordingly. For future studies, analysis can be done with more observations by expanding observation span.

\section{REFERENCES}

Bayramoğlu, M. M. (2018). Türkiye'de oduna dayalı orman ürünleri üzerine bir araştırma: zaman serisi analizi. Artvin Çoruh Üniversitesi Orman Mühendisliği Dergisi, 1: 18 - 26. DOI: 10.17474/artvinofd.333344

Cai, J., Li, H. (2007). Dependence properties and bounds for ruin probabilities in multivariate compound risk models. Journal of Multivariate Analysis, 98: 757-773. DOI: 10.1016/j.jmva.2006.06.004

Cossette, H., Marceau, E., Deschamps, W. M. (2010). Discrete-Time risk models based on time series for count random variables. The Journal of International Actuarial Association, 40(1): 123-150. DOI: 10.2143/AST.40.1.2049221

Dağlıoğlu, S., Erdemir, C. (2008a). Bazı bağımlı aktüeryal risk süreçlerinin deneysel sonuçları. İstatistikçiler Dergisi, 2: 105 - 124. Retrieved from http://www.istatistikciler.org/dergi/IstDer080204.pdf

Dağlıoğlu, S., Erdemir, C. (2008b). Bağımlı aktüeryal risklerin çok değişkenli zaman serisi modeli. İstatistikçiler Dergisi, 1: 144 - 163. Retrieved from http://dergipark.gov.tr/download/article-file/105645

Gu, C. (2013). The ruin problem of dependent risk model based on copula function. Journal of Chemical and Pharmaceutical Research, 5(9): 234-240. Retrieved from http://www.jocpr.com/articles/the-ruin-problem-of-dependent-risk-model-based-on-copula-function.pdf

Heilpern, S. (2009). Probability of ruin for a dependent, two-dimensional poisson process. Operations Research And Decision, $1: 77$ - 90. Retrieved from https://www.researchgate.net/publication/227653942_Probability_of_ruin_for_a_dependent_twodimensional_poisson_process

Jiang, W., Yang, Z. (2016). The maximum surplus before ruin for dependent risk models through farlie-gumbel-morgenstern copula. Scandinavian Actuarial Journal, 2016(5): 385-397. DOI: 10.2139/ssrn.2460490

Liosel S. and Lefevre C. (2009). Finite-Time ruin probabilities for discrete, possibly dependent, claim severities. Methodology And Computing In Applied Probability, 11(3): 425-441. DOI: 10.1007/s11009-009-9123-9

Makridakis, S., Wheelwright, S. C., Hyndman, R. J. (1998). Forecasting: methods and applications. John Wiley \& Sons. Inc, United State of America.

Tse, Yiu-Kues (2009). Nonlife actuarial models theory, methods and evaluation. Cambridge Unıversity Press, New York.

Wan, L. M., Yuen, K. C., Li, W. K. (2005). Ultimate ruin probability for a time-series risk model with dependent classes of insurance business. Journal of Actuarial Practice, 12: 193-214. Retrieved from http://digitalcommons.unl.edu/cgi/viewcontent.cgi?article=1027\&context=joap

Wang, S., Dhaene, J. (1998). Comonotonicity, correlation order and premium principles. Insurance: Mathematics and Economics, 22: 235 242. DOI: $10.1016 / \mathrm{S} 0167-6687(97) 00040-1$

Wu, X. W., Yuen, K. C. (2003). A discrete-time risk model with interaction between classes of business. Insurance: Mathematics and Economics, 33: 117-133. DOI: 10.1016/S0167-6687(03)00148-3

Yang, H. (2003). Ruin theory in a financial corporation model with credit risk. Insurance: Mathematics and Economics, 33: 135-145. DOI: 10.1016/S0167-6687(03)00149-5

Yang, H., Zhang, L. (2006). Ruin problems for a discrete time risk model with random interest rate. Mathematical Methods of Operations Research, 63(2): 287-299. DOI: 10.1007/s00186-005-0025-5

Zhang, Z., Yuen, K. C., Li, W. K. (2007). A Time-Series risk model with constant interest for dependent classes of business. Insurance: Mathematics and Economics, 41: 32-40. DOI: 10.1016/j.insmatheco.2006.08.006 